filled in a similar book and the observers had to be content with paying a daily visit to each one's home. In parallel with the collection of information about energy expenditure, food intake was studied by weighing everything eaten throughout the week of survey. The calorie value of the diet and its nutritional composition were calculated from food Tables.

The thoroughness of the whole investigation makes it a model of its kind. Information reported in detail of the energy expenditure for different kinds of activity represents a valuable addition to the literature, where, all too often, figures derived from long-forgotten experiments have been copied from one authority to another. An interesting observation arising from a statistical review of the data is that there is a highly significant relationship between the expenditure of energy for many kinds of activity and the body weight of the men carrying them out. This holds not only for walking, where a man is obviously carrying himself about, but also for such work as hewing coal and "girdering".

The average estimated energy expenditure of the miners of 3,660 calories a day compares with 3,820 and 3,360 calories for German miners studied in 1943-44 and with 4,070 calories estimated by Moss for English miners in 1935. It is interesting to notice that in comparing the nutritional value of the diet with the British Medical Association's estimate of what a good diet ought to provide, no strictures were passed on the vitamin C content, which used to be a traditional target for doubts. The only possible weakness suspected in some few instances was as to whether there was enough riboflavin.

More and more in up-to-date industries machines are used in place of men to do mechanical work. In this coal-mine in Fife the energy expenditure of clerks and miners outside their working hours was almost identical. At work, however, the miners used 1,750 calories a day and the clerks 890 calories. Yet, as the authors point out, for three hours out of the eight-hour shift the miners could do no work because for much of this time breakdown of the mechanical haulage system prevented their doing so. Moss assessed how low was the mechanical efficiency of a man shovelling coal while crouching in a mine. No such calculations were made in the present study. Nevertheless, in addition to the debt we owe to the authors of this valuable piece of physiological investigation, we shall owe them more if it enables us to relate in terms of modern engineering logic the human energetics of coal-mining to the job to be done.

\section{Magnus Pyke}

The Protection of Workers against Ionising Radiations. Report submitted to the International Conference on the Peaceful Uses of Atomic Energy, August, 1955. (Pp.66 ; 11 figures. 50 cents ; 3s.) Geneva : International Labour Office. 1955.

It is greatly to the credit of the International Labour Organization that it was able, at short notice, to produce this useful summary of the problems of radiation protection in time for the International Conference on the Peaceful Uses of Atomic Energy in August, 1955. Although little originality can be claimed for the material of the report, it is a welcome addition to the general literature on this subject and it will be of immediate interest, particularly to those who are contemplating these problems for the first time.

From an outline of the hazards of radiation work, the report goes on to consider the essential problems of radiation protection and it describes the special precautions appropriate to a range of the more common applications of radiation in industry, medicine, and agriculture. With the rapid expansion of the uses of radioactive substances there is growing concern about the safe transport of these materials, and the report contains an interesting section on this subject.

The authors are to be congratulated upon the fact that they have refrained from adding to the confusion which surrounds the genetic implications of irradiation. The list of references is surprisingly brief and will barely satisfy the keen student of this subject. It is apparent that the International Labour Organization and International Commission on Radiological Protection have many common interests ; even now, they are being joined by the World Health Organization. It may be that the time is not far distant when some formal agreement will be required to clarify the relative responsibilities of these three bodies.

\section{A. Maclean}

Clinical Orthopaedics, Number Five. Edited by Anthony F. DePalma. (Pp. viii + 242; 158 figures. $40 s$. per copy subscriptions ; single copies 60s.) Philadelphia and Montreal : J. B. Lippincott Company; London: Pitman Medical Publishing Co., Ltd. 1955.

In 1953 a group of distinguished American orthopaedic surgeons launched an unusual periodical, of which this is the fifth issue. Each number appears in book-form, cloth-bound, and so far two have appeared each year. Each has been divided into two sections, a collection of essays on one particular orthcpaedic topic being followed by a series of papers on miscellaneous orthopaedic subjects.

This fifth issue, which was published in late July, 1955, devotes its first section and three-quarters of its pages to 17 papers on backache and associated problems. There can hardly be a subject in the whole field of medicine which gives more difficulty more often to more practitioners in almost all fields, and it must be said at once that these essays will prove stimulating to anyone who is interested in the back. The orthopaedic surgeon, to whom they are primarily directed, will find much help in these pages and this issue, like its predecessors, is an essential book for any reasonably comprehensive orthopaedic library.

Your reviewer feels bound to doubt the real practical value, though not the interest, of this publication to the industrial medical officer. Four of the papers in the first section are mainly or wholly concerned with operative techniques, four others offer rather personal views on physical treatment and on manipulation, another is devoted to the evolution of the back, and one more is purely biographical. There is sound sense and good advice in T. A. Willis's paper on "The Inadequate 